\title{
PENGARUH PRODUKSI SEKTOR PERTANIAN TERHADAP PRODUKSI SUBSEKTOR INDUSTRI PERTANIAN PROVINSI JAWA BARAT
}

\author{
Juri Juswadi \\ Program Studi Agribisnis, Fakultas Petanian, Universitas Wiralodra \\ jurijuswadi@unwir.ac.id
}

\begin{abstract}
ABSTRAK
Sektor pertanian memiliki peran ganda dalam pembangunan ekonomi regional maupun nasional. Selain sebagai sumber pangan, sektor pertanian juga berperan dalam Produk Domestik Regional Bruto (PDRB), penyerapan tenaga kerja, maupun sumber bahan baku subsektor agroindustri. Provinsi Jawa Barat memiliki sumberdaya pertanian yang besar sehingga produksinya mampu berperan dalam memenuhi kebutuhan untuk dikonsumsi langsung maupun sebagai bahan baku subsektor agroindustri. Penelitian ini bertujuan untuk mengetahui peran produksi subsektor pertanian terhadap produksi subsektor agroindustri Provinsi Jawa Barat. Metode penelitian adalah kausal komparatif, dengan menggunakan data PDRB subsektor-subsektor dalam sektor Pertanian dan Subsektor Agroindustri Provinsi Jawa Barat periode 2000-2016. Analisis data menggunakan regresi linier berganda. Hasil penelitian menunjukkan produksi subsektor Tanaman Bahan Makanan berpengaruh sangat nyata terhadap produksi subsektor industri Makanan, Minuman dan Tembakau Provinsi Jawa Barat, sedangkan subsektor Peternakan dan Hasil-hasilnya serta subsektor Perikanan berpengaruh nyata. Produksi Subsektor Tanaman Perkebunan serta Subsektor Peternakan dan Hasil-hasilnya berpengaruh sangat nyata terhadap produksi subsektor Industri Tekstil, Barang Kulit dan Alas Kaki Provinsi Jawa Barat. Produksi Subsektor Tanaman Perkebunan berpengaruh sangat nyata terhadap produksi subsektor industri Kertas dan Barang Cetakan Provinsi Jawa Barat.
\end{abstract}

Kata kunci: sektor pertanian, subsektor agroindustri, Produk Domestik Regional Bruto (PDRB)

\section{PENDAHULUAN}

Sektor pertanian Provinsi Jawa Barat tetap penting dalam menyediakan kebutuhan pangan dan non pangan, pendapatan domestik, dan penyerapan tenaga kerja. Kebutuhan tersebut berasal dari lima subsektor dalam sektor pertanian yaitu subsektor: 1.Tanaman Bahan Makanan, 2.Tanaman Perkebunan, 3.Peternakan dan Hasil-hasilnya, 4.Kehutanan, dan 5.Perikanan. Selain dikonsumsi langsung produk primer subsektor-subsektor pertanian tersebut juga diolah menjadi produk pangan dan non pangan olahan yang memberikan nilai tambah bagi sektor industri pengolahan produk pertanian (agroindustri). Subsektor agroindustri Provinsi Jawa Barat akan mempercepat proses tranformasi struktural, yaitu dari provinsi dengan kontribusi sektor pertanian yang tinggi dalam PDRB, menjadi berkurang digantikan oleh meningkatnya kontribusi subsektor agroindustri. Proses ini akan meningkatkan pendapatan dan kesejahteraan para pekerja di subsektor agroindustri.

Melihat kenyataan ini, maka upaya peningkatan produksi subsektor agroindustri menjadi penting melalui peningkatan produksi sektor pertanian. Industri Pengolah meliputi kegiatan ekonomi dibidang pengolahan dari bahan mentah menjadi produk baru. Bahan baku industri pengolahan berasal dari produk pertanian, produk kehutanan, produk perikanan,dan produk pertambangan atau penggalian seperti produk dari kegiatan industri pengolahan lainnya.Industri yang bergerak dibidang pengolahan digambarkan sebagai pabrik, yang menggunakan mesin atau peralatan yang khusus, yaitu yang mengubah bahan mentah menjadi produk baru, dan kegiatan penjualan produk yang dibuat di tempat yang sama dan melakukan pengolahan bahan-bahan dari pihak luar atas dasar kerjasama kontrak (KBLI, 2015) 
Data Tabel 1. menunjukkan peningkatan produksi dari tahun 2000 ke tahun 2015, kecuali produksi subsektor Tanaman Bahan Makanan menurun pada tahun 2015. Keadaan ini mencerminkan pertumbuhan ekonomi yang baik sepanjang periode tersebut

Tabel 1. PDRB Subsektor Pertanian dan Agroindustri Provinsi Jawa Barat Atas Dasar Harga Konstan Tahun 2000 dan 2010 (Jutaan Rupiah)

\begin{tabular}{lrrrr}
\hline Sektor Pertanian dan Industri & 2000a) & 2005a) & 2010a) & 2015b) \\
Agro & & & & \\
\hline Subsektor Pertanian & & & & \\
1. Tanaman Bahan Makanan & 21.519 .9 & 25.489 .7 & 31.947 .2 & 44.827 .8 \\
2. Tanaman Perkebunan & 69,49 & 06,18 & 47,00 & 50,00 \\
3. Peternakan dan Hasil- & $1.564 .153,44$ & 1.898 .28 & 2.163 .25 & 8.468 .76 \\
hasilnya & 3.991 .16 & 0,64 & 3,00 & 0,00 \\
4. Kehutanan & 2,48 & 5.275 .52 & 5.555 .84 & 12.304 .7 \\
5. Perikanan & 266.312, & 5,07 & 1,00 & 60,00 \\
& 05 & 207.241, & 377.535, & 889,760, \\
& 1.442 .58 & 22 & 00 & 00 \\
& 9,13 & 1.820 .48 & 2.093 .61 & 10.601. \\
& & 6,55 & 0,00 & 990,00 \\
Sektor Industri Pengolahan & & & & \\
Agro & 5.255 .95 & 12.262 .5 & 14.388 .1 & $55.606 .320,00$ \\
1. Makanan, Minuman dan & 9,83 & 84,78 & 96,00 & $74.897 .660,00$ \\
Tembakau & 14.055 .7 & 24.986 .3 & 244.695, & 12.092 .4 \\
2. Tekstil, Barang Kulit dan & 76,54 & 34,19 & 03 & 10,00 \\
Alas Kaki & 573.402, & 1.483 .09 & 1.594 .76 & 28.374 .1 \\
3. Kertas dan Barang & 40 & 4.94 & 2,00 & 40,00 \\
Cetakan & 2540372 & 2.719 .60 & 3.454 .33 & 41.890 .5 \\
4. Pupuk, Kimia dan Barang &, 06 & 7,61 & 2,00 & 00,00 \\
dari Karet & 10.071 .7 & 10.823 .7 & 10.411 .8 & \\
5. Barang Kayu dan Hasil & 27,47 & 59,11 & 61,00 & \\
Hutan Lainnya & & & & \\
\hline
\end{tabular}

Sumber. Jawa Barat dalam Angka 2001-2016

a) : harga konstan tahun 2000

b) : harga konstan tahun 2010

Meningkatnya produksi subsektor-subsektor dalam sektor pertanian mendorong peningkatan produksi subsektor agroindustri. Hal ini wajar terjadi mengingat kelebihan produksi primer sektor pertanian tersebut dari konsumsi langsung dapat digunakan oleh subsektor agroindustri sebagai bahan baku. Oleh karena itu besarnya pengaruh subsektor-subsektor pertanian terhadap subsektor agroindustri penting diketahui agar dapat djadikan model dalam prediksi produksi subsektor agroindustri di masa yang akan datang. Penelitian ini dilakukan untuk mengetahui model regresi dari pengaruh subsektor-sebsektor pertanian terhadap subsektor agroindustri Provinsi Jawa Barat.

\section{KAJIAN LITERATUR}

Menurut Delgado et al. (1998) pada awalnya, pertumbuhan sektor pertanian dianggap tidak memiliki keterkaitan produksi yang akan datang dan yang sebelumnya, karena permintaan input antara dalam jumlah kecil serta adanya investasi pada aktivitas industri pengolahan (downstream industry). Kenyataan ini mengarah pada kesimpulan bahwa sektor pertanian bukan merupakan prioritas utama untuk mempercepat pertumbuhan di negara berkembang. Hal ini didasarkan pada pendapat: Hirschman bahwa investasi publik harus diarahkan pada sektor non pertanian, Prebisch mengembangkan pemikiran "anti pertanian" yang mendorong debat tentang elastisitas yang pesimis pada ekspor pertanian, serta Hazel dan Roell menyatakan bahwa sektor non pertanian memiliki 
keterkaitan produksi yang lebih tinggi terhadap ekonomi keseluruhan, yang menghasilkan pengganda (multiplier effects) tertinggi.

Studi Hirschman (1958) di Amerika Latin, merupakan studi awal tentang keterkaitan antarindustri atau antarsektor, yang difokuskan pada keterkaitan produksi. Keterkaitan tersebut adalah sebagai keterkaitan kebelakang (backward linkages) dan keterkaitan ke depan (forward linkages) yang muncul dari aktivitas produksi baru. Menurut Johnston dan Mellor (1961), peranan sektor pertanian dalam percepatan pertumbuhan ekonomi adalah melalui: peningkatan suplai pangan bagi permintaan domestik, penyediaan tenaga kerja bagi perindustrian, perluasan ukuran pasar bagi output perindustrian, peningkatan tabungan domestik, dan perolehan devisa.

Menurut Melor (1966) walaupun keterkaitan dari produksi sektor pertanian khususnya pertanian subsisten masih lemah, yang ditandai oleh kecilnya pengaruh langsung terhadap pertumbuhan sektor di luar pertanian, keterkaitan konsumsi dari sektor pertanian secara nyata memiliki pengaruh tidak langsung terhadap perekonomian.

Paling tidak terdapat lima mekanisme keterkaitan ekonomi antara sektor pertanian dan non pertanian (Rangrajan, 1982), yaitu:

1. Sektor pertanian menghasilkan bahan baku bagi sektor non pertanian. Produksi sektor pertanian berupa bahan konsumsi dan non konsumsi dan non konsumsi merupakan input utama bagi sektor non pertanian seperti industri pengolahan hasil pertanian (agroindustri), sektor perdagangan, dan restoran;

2. Sektor non pertanian menghasilkan input yang diperlukan setor pertanian. Pupuk, pestisida, mesin dan peralatan pertanian, dan berbagai jenis jasa merupakan hasil sektor non pertanian yang menjadi input sektor pertanian.

3. Sektor pertanian (rumah tangga pertanian) merupakan pasar bagi output akhir sektor non pertanian. Bahan pangan olahan, sandang dan papan serta berbagai jenis jasa yang dihasilkan sektor non pertanian, dikonsumsi oleh rumah tangga pertanian.

4. Keterkaitan melalui tabungan pemerintah dan investasi publik. Peningkatan output sektor pertanian akan secara langsung meningkatkan penerimaan pajak tak langsung pemerintah yang selanjutnya digunakan untuk membiayai investasi publik. Peningkatan investasi publik ini akan menignkatkan permintaan barang-barang modal yang dihasilkan sektor non pertanian.

5. Keterkaitan melalui perilaku investasi swasta. Harga komoditas pertanian yang relatif rendah dan tidak stabil, akan merangsang investasi swasta di sektor non pertanian. Sebaliknya kenaikan harga komoditas pertanian akan mengurangi insentif investasi swasta pada sektor non pertanian. Hal ini karena nik turunnya harga komoditas pertanian akan meningkatkan atau menurunkan biaya produksi sektor non pertanian baik melalui kenaikan atau penurunan biaya bahan baku maupun upah tenaga kerja.

Studi Bank Dunia (Timer, 1988) tentang keterkaitan pertumbuhan antara pertanian dan non pertanian mengungkapkan bahwa dari 23 negara yang pangsa sektor pertaniannya dalam PDB lebih dari $20 \%$ dan laju pertumbuhan PDB lebih dari 5\% pertahun; 17 negara mengalami pertumbuhan sektor pertanian lebih dari 3 persen pertahun, sedangkan 11 negara yang mengalami pertumbhan PDB kurang dari 3 persen per tahun, tingkat pertumbuhan sektor pertanian hanya mencapai satu persen atau kurang. Fenomena ini terkecuali pada negara-negara yang perekonomiannya bersumber dari migas dan bahan tambang dimana pertumbuhan PDB yang cepat disertai oleh pertumbuhan sektor pertanian yang lambat.

Daryanto dan Morison (1992) menyatakan bahwa studi saling ketergantungan (interdependency) sejak tahun enampuluhan menggambarkan pentingnya keterkaitan antara bidang pertanian dan bidang ekonomi lainnya, dan menunjukkan bahwa keterkaitan tersebut meningkat seiring dengan pertumbuhan ekonomi. Sebagai contoh, adanya stagnasi dalam pertanian dapat menghalangi pertumbuhan industri, melalui pembatasan pasokan produk pertanian yang dibutuhkan untuk menunjang pertumbuhan sektor industri. Sementara stagnasi dalam perindustrian menghambat pembangunan pertanian, melalui pembatasan sumberdaya dari sektor tersebut yang dibutuhkan pertanian dalam meningkatkan pertumbuhannya.

Hasil penelitian Juswadi (2010) mengungkapkan bahwa pangsa PDRB subsektor agroindustri yang berpengaruh nyata positif pada $\alpha 0,10$ terhadap pangsa PDRB sektor industri adalah subsektor industri produk makanan, produk minuman, dan produk tembakau dan subsektor industri produk kayu

Jurnal Agri Wiralodra 
dan hasil produk hutanjawa baratlainnya. Peran subsektor agroindustri tersebut menempatkannya sebagai subsektor yang penting (unggulan) di Provinsi Jawa Barat.

Lains (1989) dan Simatupang (1997) dalam Suryana et al (1998) mengemukakan bahwa Indonesia mengalami penurunan di bidang pertanian dan bidang industri. Selama periode tahun 1971 sampai 1990, hubungan produk antar industri dalam bidang pertanian mengalami penurunan tajam.

\section{METODE PENELITIAN}

Metode penelitian ini menggunakan metode kausal komparatif untuk melihat pengaruh variable bebas (independen) subektor-subsektor pertanian (Subsektor Tanaman Bahan Makanan, Subsektor Tanaman Perkebunan, Subsektor Peternakan dan Hasil-hasilnya, Subsektor Perikanan, dan Subsektor Kehutanan) terhadap variable tidak bebas (dependen) subsektor agroindustri (Subsektor Industri Makanan, Minuman dan Tembakau, Subsektor Industri Tekstil, Barang Kulit dan Alas Kaki, Subsektor Industri Kertas dan Barang Cetakan, Subsektor Industri Pupuk, Kimia dan Barang dari Karet, dan Subsektor Industri Barang Kayu dan Hasil Hutan Lainnya). Alat analisis yang digunakan adalah model persamaan regresi linier berganda.

Penelitian ini menggunakan data sekunder Nilai PDRB Subsektor Tanaman Bahan Makanan, Subsektor Tanaman Perkebunan, Subsektor Peternakan dan Hasil-hasilnya, Subsektor Perikanan, Subsektor Kehutanan, Subsektor Industri Makanan, Minuman dan Tembakau, Subsektor Industri Tekstil, Barang Kulit dan Alas Kaki, Subsektor Industri Kertas dan Barang Cetakan, Subsektor Industri Pupuk, Kimia dan Barang dari Karet, dan Subsektor Industri Barang Kayu dan Hasil Hutan Lainnya Provinsi Jawa Barat periode 2000-2016. Data penelitian diperoleh dari publiaksi Jawa Barat Dalam Angka Tahun 2001-20016.

\section{HASIL DAN PEMBAHASAN}

Hasil regresi antara subsektor Tanaman Bahan Makanan, Tanaman Perkebunan, Peternakan dan Hasil-hasilnya, Kehutanan, dan Perikanan, terhadap subsektor industri Makanan, Minuman dan Tembakau ditunjukkan oleh persamaan: $\mathrm{Y}_{1}=-12.170 .330,41+0.575 \mathrm{X}_{1}+1.009 \mathrm{X}_{3}+1.957 \mathrm{X}_{5}+\mu$ $\mathrm{Y}_{1}$ :Subsektor industri Makanan, Minuman dan Tembakau

$\mathrm{X}_{1}$ : Subsektor Tanaman Bahan Makanan,

$\mathrm{X}_{3}$ : Subsektor Peternakan dan Hasil-hasilnya,

$\mathrm{X}_{5}$ : Subsektor Perikanan

Produksi subsektor Tanaman Bahan Makanan Provinsi Jawa Barat berpengaruh sangat nyata terhadap produksi subsektor industri Makanan, Minuman dan Tembakau Provinsi Jawa Barat dengan koefisien regresi 0,575. Demikian pula subsektor Peternakan dan Hasil-hasilnya serta subsektor Perikanan Provinsi Jawa Barat berpengaruh nyata terhadap subsektor industri Makanan, Minuman dan Tembakau Provinsi Jawa Barat dengan koefisien regresi 1.009 dan 1.957. Model persamaan regresi ini juga berati bahwa adanya peningkatan produksi subsektor Tanaman Bahan Makanan sebesar Rp 100 juta, dengan asumsi produksi yang tetap pada subsektor Peternakan dan Hasil-hasilnya serta subsektor Perikanan, maka produksi subsektor industri Makanan, Minuman dan Tembakau Provinsi Jawa Barat akan meningkat sebesar Rp 45.329.670,00. Adanya peningkatan produksi di sub bagian Peternakan dan Hasil-hasilnya sebesar Rp 100 juta, dengan asumsi produksi yang tetap pada sub bagian bidang Tanaman Bahan Makanan serta subsektor Perikanan, maka produksi subsektor industri Makanan, Minuman dan Tembakau Provinsi Jawa Barat akan meningkat sebesar Rp 88.729.670,00. Adanya peningkatan produksi sektor subsektor Perikanan sebesar Rp 100 juta, dengan asumsi produksi yang tetap pada subsektor Tanaman Bahan Makanan serta subsektor Peternakan dan Hasil-hasilnya, maka produksi subsektor industri Makanan, Minuman dan Tembakau Provinsi Jawa Barat akan meningkat sebesar Rp 183.529670,00.

Hasil regresi antara subsektor Tanaman Perkebunan serta subsektor Peternakan dan Hasilhasilnya, terhadap subsektor Industri Tekstil, Barang Kulit dan Alas Kaki ditunjukkan oleh persamaan: $\mathrm{Y}_{2}=118684.310+6.376 \mathrm{X}_{2}+2.197 \mathrm{X}_{3}+\mu$

$\mathrm{Y}_{2}$ :Subsektor Industri Tekstil, Barang Kulit dan Alas Kaki 
$\mathrm{X}_{2}$ : Subsektor Tanaman Perkebunan,

$\mathrm{X}_{3}$ : Subsektor Peternakan dan Hasil-hasilnya,

Produksi Subsektor Tanaman Perkebunan serta Subsektor Peternakan dan lainnya, Provinsi Jawa Barat berpengaruh sangat nyata terhadap produksi subsektor Industri Tekstil, Barang Kulit dan Alas Kaki Provinsi Jawa Barat dengan koefisien regresi 6.376 dan 2.197. Model persamaan regresi ini juga berati bahwa adanya peningkatan produksi subsektor Tanaman Perkebunan sebesar Rp 100 juta, dengan asumsi produksi yang tetap pada subsektor Peternakan dan Hasil-hasilnya, maka produksi subsektor industri Tekstil, Barang Kulit dan Alas Kaki Provinsi Jawa Barat akan meningkat sebesar Rp 637.481.316,69. Adanya peningkatan produksi subsektor Peternakan dan Hasil-hasilnya sebesar Rp 100 juta, dengan asumsi produksi yang tetap pada subsektor Tanaman Perkebunan, maka produksi subsektor industri Tekstil, Barang Kulit dan Alas Kaki Provinsi Jawa Barat akan meningkat sebesar Rp 219.581.315,69

Hasil regresi antara subsektor Tanaman Perkebunan terhadap subsektor Industri Kertas dan Barang Cetakan ditunjukkan oleh persamaan: $\mathrm{Y}_{3}=-735.273,728+0,272 \mathrm{X}_{2}+\mu$;

$\mathrm{Y}_{3}$ : Subsektor Industri Kertas dan Barang Cetakan

$\mathrm{X}_{2}$ : subsektor Tanaman Perkebunan,

Produksi Subsektor Tanaman Perkebunan Provinsi Jawa Barat berpengaruh sangat nyata terhadap produksi subsektor industri Kertas dan Barang Cetakan Provinsi Jawa Barat dengan koefisien regresi 0,272. Model persamaan regresi ini juga berati bahwa adanya peningkatan produksi subsektor Tanaman Perkebunan sebesar Rp 100 juta maka produksi industri Kertas dan Barang Cetakan Provinsi Jawa Barat akan meningkat sebesar Rp 26.464.726,27. Melalu prediksi persamaanpersamaan regresi ini maka dapat diupayakan peningkatan produksi subsektor agroindustri yang diharapkan melalui peningkatan produksi subsektor-subsektor pertanian.

\section{SIMPULAN DAN SARAN}

Produksi subsektor Tanaman Bahan Makanan berpengaruh sangat nyata terhadap produksi subsektor industri Makanan, Minuman dan Tembakau Provinsi Jawa Barat, sedangkan subsektor Peternakan dan Hasil-hasilnya serta subsektor Perikanan berpengaruh nyata. Produksi Subsektor Tanaman Perkebunan serta Subsektor Peternakan dan Hasil-hasilnya berpengaruh sangat nyata terhadap produksi subsektor Industri Tekstil, Barang Kulit dan Alas Kaki Provinsi Jawa Barat. Produksi Subsektor Tanaman Perkebunan berpengaruh sangat nyata terhadap produksi subsektor industri Kertas dan Barang Cetakan Provinsi Jawa Barat. Berdasrkan model persamaan regresi yang dihasilkan, disarankan untuk meningkatkan produksi Subsektor Tanaman Bahan Makanan, Subsektor Tanaman Perkebunan, Subsektor Peternakan dan Hasil-hasilnya, Subsektor Perikanan untuk meningatkan produksi subsektor Industri Makanan, Minuman dan Tembakau, Subsektor Industri Tekstil, Barang Kulit dan Alas Kaki, serta Subsektor Industri Kertas dan Barang Cetakan.

\section{Ucapan Terimakasih}

Ucapan Terimaksih saya ucapkan kepada pihak terkait dalam penelitian ini baik eksternal maupun internal yang telah membantu penelitian .

\section{DAFTAR PUSTAKA}

BPS Popinsi Jawa Barat. 2002. Jawa Barat Dalam Angka 2001. Bandung BPS Popinsi Jawa Barat . 2003. Jawa Barat Dalam Angka 2003. Bandung BPS Popinsi Jawa Barat . 2005. Jawa Barat Dalam Angka 2004/2005. Bandung BPS Popinsi Jawa Barat . 2006. Jawa Barat Dalam Angka 2006. Bandung BPS Popinsi Jawa Barat . 2007. Jawa Barat Dalam Angka 2007. Bandung BPS Popinsi Jawa Barat . 2008. Jawa Barat Dalam Angka 2008. Bandung BPS Popinsi Jawa Barat . 2009. Jawa Barat Dalam Angka 2009. Bandung BPS Popinsi Jawa Barat . 2010. Jawa Barat Dalam Angka 2010. Bandung BPS Povinsi Jawa Barat . 2012. Jawa Barat Dalam Angka 2011. Bandung 
BPS Popinsi Jawa Barat . 2012. Jawa Barat Dalam Angka 2012. Bandung

BPS Popinsi Jawa Barat . 2014. Jawa Barat Dalam Angka 2014. Bandung

BPS Popinsi Jawa Barat . 2006. Provinsi Jawa Barat Dalam Angka 2016 Bandung

BPS Popinsi Jawa Barat . 2006. Provinsi Jawa Barat Dalam Angka 2016 Bandung

BPS. 2015. Klasifikasi Baku Lapangan Usaha Indonesia (KBLI). Jakarta

Daryanto, A. and J.B. Morison. 1992. Structural interdependence in the Indonesiaan Economy, with Emphasis on the Agricultural Sector, 1971-1985: an Input-Output Analysis. Mimbar Sosek 6:74-99. Jurusan Ilmu Sosek Pertanian. IPB. Bogor.

Delgado, C.L., J. Hopkins., and V.A. Kelly. 1989. Agricultural Growth Linkages in Sub-Saharan Africa. International Food Policy Research Institute Washington DC.

Hirschman, A.O. 1958. The Strategy of Economics Development. New Haven, Yale University.

Juswadi, J. 2010. Peran Agroindustri Jawa Barat dalam Proses Transformasi Struktural. Jurnal Agri Wiralodra. Volume 2 No. 1. Tahun 2010. Indramayu.

Melor, J.W. 1966. The Economics of Agricultural Development. Cornell University Press. IthacaNewYork.

Rangarajan, C. 1982. Agricultural Growth and Industrial Performance in India. International Food Policy Research Institute. Washington.

Suryana et al. 1998. Kebijakan Peningkatan Produktivitas dan Pertumbuhan Agroindustri Pedesaan, Pusat Penelitian Sosial Ekonomi Pertanian, Badan Penelitian dan Pengembangan Pertanian.

Timmer, C.P. 1988. The Agricultural Transformation, In: Handbook of Development Economic. Volume 1. Elsvier Science Publisher. B.V. Amsterdam. 